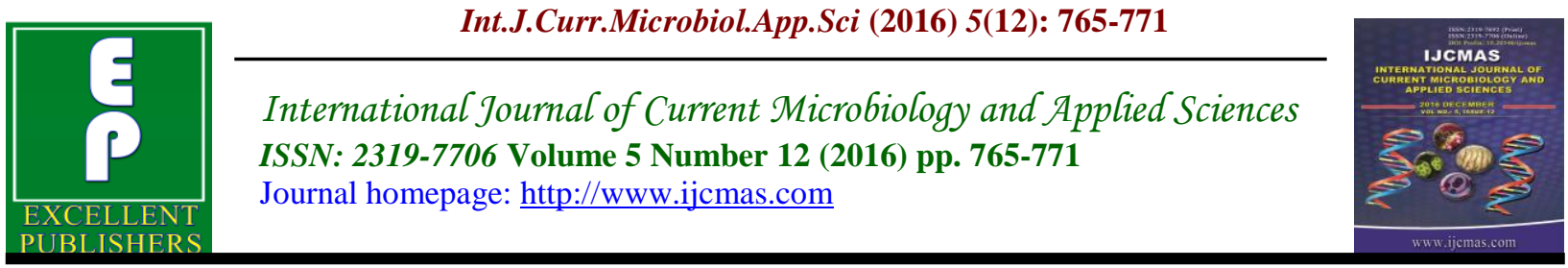

Original Research Article

http://dx.doi.org/10.20546/ijcmas.2016.512.087

\title{
Synthesis Some Pyrimidine Derivatives Act as Chelating Agents for Lead Masking
}

\author{
Salman A. Ahmed and Zainab N. Eyada* \\ Department of Chemistry, College of Science, Al-Nahrain University, Baghdad, Iraq \\ *Corresponding author
}

Keywords

Pyrimidine derivatives, chelating agent, lead masking.

Article Info

Accepted:

28 November 2016

Available Online:

10 December 2016

\section{A B S T R A C T}

Chelation is a type of bonding of ions and molecules to metal ions. Usually found as organic or inorganic compounds capable of binding metal ions to form complex ring-like building called 'chelates' to remove lead, chelating agents that form strong bonds to heavy metals can be utilized. Calcium disodium EDTA (CaNa2EDTA), D-penicillamine, dimercaprol (BAL and 2,3-dimercaptosuccinic acid (DMSA or succimer) have been used as clinical chelating agents for $\mathrm{Pb}$ (II This study was conducted to study the effect of chelating agent to the lead masking. This study was prepare some compounds act as chelating agents for lead masking and prepare standard solutions for lead than react the standard solutions with chelating agent. The results of the study showed a high-significant decrease lead when it react with some pyrimidine derivatives that act as chelating agent with lead.

\section{Introduction}

Chelation is a type of bonding of ions and molecules to metal ions (Book, 2014). Usually found as organic or inorganic compounds capable of binding metal ions to form complex ring-like building called 'chelates'. Chelating agents have "ligand" binding atoms that form either two covalent linkages or one covalent, one coordinate or two coordinate bonds in the case of bidentate chelates. Mainly atoms like S, N and $\mathrm{O}$ task as ligand atoms in the form of chemical groups like $-\mathrm{SH},-\mathrm{S}-\mathrm{S},-\mathrm{NH} 2$, $=\mathrm{NH},-\mathrm{OH},-\mathrm{OPO} 3 \mathrm{H}$, or $>\mathrm{C}=\mathrm{O}$. Bi denote or multi dentate ligands procedure ring structures that include the metal ion and the two-ligand atoms attached to the metal (Flora, 2010).
To remove lead, chelating agents that form strong bonds to heavy metals can be utilized. Chelation therapy has been mainly used for lead(II) detoxification since the early 1950s.Calcium disodium EDTA (CaNa2EDTA), D-penicillamine, dimercaprol (BAL (and 2,3-dimercaptosuccinic acid (DMSA or succimer) have been used as clinical chelating agents for $\mathrm{Pb}$ (II), with Dpenicillamine being the only orally administered drug available until succimer in 1991. so chelating agents to be used as antidotes against lead toxicity (Sisombath, 2014).

Several chelating agents are active in lead excretion, but the chelator of choice depends on the blood lead concentration, the 
patient's symptoms and the ecological lead burden. Symptomatic patients should be hospitalized and chelation therapy with Edetate Calcium Disodium (CaNa2EDTA). $\mathrm{CaNa2EDTA}$ is an intravenous formulation that has been shown to be effective with British AntiLewisite (BAL, Dimercaprol) for elimination of lead in patients with encephalopathy. Edetate calcium disodium, used alone, may aggravate signs in patients with very great blood lead levels. When clinical symptoms consistent with lead poisoning or as soon as blood lead levels are larger than 70 micrograms/deciliter, it is recommended that edetate calcium disodium be used in conjunction with dimercaprol (Lowry, 2010). British-Anti-Lewisite (BAL) or dimercaprol is a small molecule drug which will pass into cells and may avoid the worsening of clinical and biochemical status on the first day of EDTA therapy (Chisolm, 1971).

Ideally the chelating agent should possess the following characteristics:

-potent affinity for the poisonous metal to be chelated

-Ability to chelate with natural chelating groups found in biological system

-Small toxicity

- Capability to penetrate cell membrane to reach site of toxic metal deposit

-Minimal metabolism

-Rapid elimination of metal

-High water solubility (Srivastava, 2010).

\section{Materials and Methods}

The steps of synthesizing these compounds represented the classical method (scheme 1,2) Three necked, round-bottomed flask mounted in a heating mantle is fitted with a $250 \mathrm{ml}$. dropping funnel, an efficient, sealed, mechanical stirrer, and a reflux condenser connected to calcium chloride drying tube. Absolute ethanol $(62.5 \mathrm{ml})$ is placed in the flask, the stirrer is started, and $2.3 \mathrm{~g}$. (0.1 g atom) of freshly cut sodium is added in portions.

After the sodium has dissolved, 7.61g ( 0.1 mole) of thiourea is added to the warm, stirred solution in one portion. When the bulk of the thiourea has dissolved, $16.9 \mathrm{~g}$ ( 0.1 mole) of liquefied ethyl ethoxymethylenecyanoacetate is added from the dropping funnel to the stirred mixture over a period of 2 hours (Ethyl ethoxymethylenecyano- acetate can be prepared in laboratory from ethyl cyan acetate and ethyl orthoformate according to the directions of de bellemont. The submitters and checkers used a commercial product, m.p. $45-50^{\circ}$, obtained from kayfries, Inc., New York. The liquefied product is weighed and poured in to the dropping funnel. An infrared heating lamp is used to keep it liquid during the addition.)

This rat of addition keeps the reaction mixture warm. The solution is then stirred and gently refluxed for 6 hours. The sodium salt of the carbethoxypyrimidine may precipitate during the course of the reaction. The reaction mixture is cooled to $50-60^{\circ}$, and $0.175 \mathrm{~L}$ of water is adding, followed by $6.5 \mathrm{ml}$. of acetic acid to make the mixture distinctly acidic. The resulting suspension is stirred and boiled for 5 minutes' order to effect complete decomposition of the sodium salt.

The mixture is cooled to $25^{\circ}$, and the crystalline 2-mercapto-4-amino -5carbethoxypyrimidine and can be collected. Buchner funnel and washed successively with five $5 \mathrm{ml}$. portions of water $5 \mathrm{ml}$ of acetone, and $5 \mathrm{ml}$. of ether(For complete removal of a yellow impurity, the product 
should be stirred well with each portion of water before filtration if the solid is not washed with organic solvents, drying of caked product will be slow) after being dried for 5 hours at $110^{\circ}$ and atmospheric pressure. It is in the form of a cream-colored powder that is sufficiently pure for synthetic purposes.

The aqueous filtrate from which the crude 2mercapto-4-amino-5-carbethoxypyrimidine separated is cooled overnight at $0^{\circ}$ and the cyano pyrimidine that precipitates is collected on a suction filter, the crude product is recrystallized from about $20 \mathrm{ml}$. of $10 \%$ acetic acid with $0.1 \mathrm{~g}$. of decolorizing charcoal added.

Two additional recrystallizations done similarly give the pure cyan pyrimidine as faintly yellow crystals, (the decomposition point is greatly dependent on the rate of heating. The checkers found that the carbethoxypyrimidine heated on a Fisher Johns melting point block at a rate of $4^{\circ}$ per minute decomposed at $280-285^{\circ}$ Under the same condition the cyan pyrimidine decomposed at $285-289^{\circ}$. Both products started to darken around $260^{\circ}$.) (Blatt, 1963) three necked flask equipped with a reflux condenser and an efficient stirrer was placed. to $203 \mathrm{ml}$ of absolute ethanol (99.99\%), (8g ,0.34g. atom) of sodium,(18.5ml,0.17mole) of ethylcyanoacetate, and $(13.29 \mathrm{~g}, 0.17 \mathrm{~mole})$ of thiourea were added. the mixture was heated under reflux for 4 hours. (203ml)of hot $\left(80^{\circ}\right)$ water was added, the stirred mixture was heated at $\left(80^{\circ}\right)$ for 15 minutes and then neutralized to litmus with glacial acetic acid .additional glacial acetic acid $(15.2 \mathrm{ml})$ was added ,followed by cautious addition of a solution of $(13.1 \mathrm{~g}, 0.19$ mole) of sodium nitrite which was dissolved in $(14.1 \mathrm{ml})$ of water. The nitrose compound was removed by filtration and washed twice with a small amount of ice water (Naji, 2013).

\section{Prepare Standard lead}

The preparation of standard solutions of lead from lead nitrate $\mathrm{Pb}(\mathrm{NO} 3) 2$

To calculate the quantity to be taken of lead nitrate to prepare standard solutions using this equation:

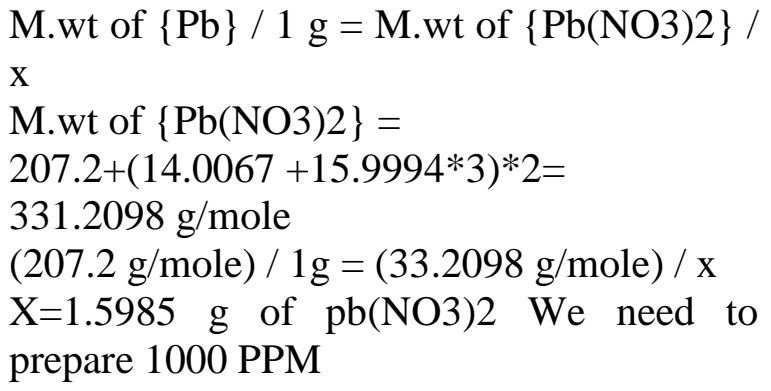
prepare $1000 \mathrm{PPM}$

Dissolve in a liter of deionized water and added 10 drops of nitric acid Center to ensure the melting of nitrates.

1-Prepare standard solution (5 P.P.M)

From the standard solution to lead (1000 p.p.m) is prepared (5 p.p.m)

According to the equation

$\mathrm{C} 1 * \mathrm{~V} 1=\mathrm{C} 2 * \mathrm{~V} 2$

$\mathrm{C} 1$ is the concertation of stock solution

$\mathrm{V} 1$ is the volume need to prepare standard

C2 is the concertation of standard

$\mathrm{V} 2$ is volume of volumetric flask

$1000 * \mathrm{~V} 1=5 * 250$

$\mathrm{V} 1=1.25 \mathrm{ml}$

Taken from the stock solution and put in volumetric flask $(250 \mathrm{ml})$ and complete to the sign Deionized water.

2-Prepare standard solution (10 P.P.M)

$\mathrm{C} 1 * \mathrm{~V} 1=\mathrm{C} 2 * \mathrm{~V} 2$

$1000 * \mathrm{~V} 1=10 * 250$

$\mathrm{V} 1=2.5 \mathrm{ml}$

Taken from the stock solution and put in volumetric flask $(250 \mathrm{ml})$ and complete to the sign Deionized water (Skoog, 2013).

After preparation of standard solutions (5, 
10) p.p.m. It has been sent to a laboratory Ibn Sinato sure of Accuracy of the results. The rate of error is about $(10 \%)$ We are mixed the organic compounds with the standard lead solutions to known the percentage linked lead with this compounds

\section{The Statistical Analysis System}

SAS (2012) program was used to study effect of difference factors in study parameters. Least significant difference LSD test was used to significant compare between means in this study

\section{Results and Discussion}

A-Synthesis of 2-mercapto-4-hydroxy-5cyanopyrimidine

It was prepared from the reaction of Ethyl ethoxy methylene cyano acetate and thiourea in a sodium ethoxide as catalysts (122) : The compound in IR (KBr) (Vmax/Cm-1) showed a wide band at $3441.01 \mathrm{~cm}^{-} 1$ which assigned to the $(\mathrm{OH})$ group. In addition the bond at $2260.57 \mathrm{~cm}^{-1}$ due to the $(\mathrm{CN})$ group. In $2422.59 \mathrm{~cm}^{-1}$ showed a weak band due to $(\mathrm{SH})$ group, $(\mathrm{C}$ $\mathrm{H})$ aromatic at $3012.57 \mathrm{~cm}^{-} 1$ and $(\mathrm{C}=\mathrm{C}$ ) and $(\mathrm{C}=\mathrm{N})$ at $1400-1600 \mathrm{~cm}^{-1},(\mathrm{C}-\mathrm{O})$ showed at $1161.15 \mathrm{~cm}^{-} 1$

B-Synthesis of 2-mercapto-4-amino-5carbethoxypyrimidine.
It was prepared from the reaction of Ethyl ethoxy methylene cyano acetate and thiourea in a sodium ethoxide as catalysts and the crude product is 2-mercapto-4amino-5-carbethoxypyrimidine Compound in IR $(\mathrm{KBr})(\mathrm{Vmax} / \mathrm{Cm}-1)$ was showed two band in $3464.15 \mathrm{~cm}^{-1}$ and $3433.29 \mathrm{~cm}^{-} 1$ were due to asymmetric and symmetric stretching vibration of (NH2) group. (C-H Ar) at $3136.25 \mathrm{~cm}^{-} 1$. The spectrum showed a band at $2561.47 \mathrm{~cm}^{-} 1$ due to $(\mathrm{SH})$ group.The bands at $2987.09 \mathrm{~cm}^{-1}$ and $2800.64 \mathrm{~cm}^{-} 1$ Could be attributed to the asymmetric and symmetric stretching vibration of $\mathrm{CH} 3$ and $\mathrm{CH} 2$ of ethyl group, while the band at $1462.04 \mathrm{~cm}^{-} 1$ and 1415.75 $\mathrm{cm}^{-1}$ can be assigned to the bending vibration of ( $\mathrm{CH} 3 \mathrm{AND} \mathrm{CH} 2)$. And the band at 1689.64 which assigned to the carbonyl stretching vibration the cause of decease this band may be return to formation of hydrogen bonding. The stretching vibration of $(\mathrm{C}-\mathrm{O}-\mathrm{C}=)$ was identified by the bands at $1080 \mathrm{~cm}^{-1}$ and $1249 \mathrm{~cm}^{-} 1$ $,(\mathrm{C}=\mathrm{C}),(\mathrm{C}=\mathrm{N})$ can appears band in 1400 $1600 \mathrm{~cm}^{-} 1$

C-Synthesis of 6-amino-2mercapto-5nitrosopyrimidin-4-ol

It was prepared from the reaction of ethylcyanoacetate with thiourea in a strong basic medium and the product is (6-amino2mercapto-5-nitrosopyrimidin-4-ol).

Table.1 Effect of components on the pb concentration

\begin{tabular}{|c|c||c||c|c|}
\hline $\begin{array}{c}\text { Conc. of } \\
\mathrm{Pb}\end{array}$ & $\mathrm{C} 1$ & $\mathrm{C} 2$ & $\mathrm{C} 3$ & P-value \\
\hline \hline $10 \mathrm{ppm}$ & 7.41 & 0.2166 & 6.832 & $0.0001 * *$ \\
\hline \hline $5 \mathrm{ppm}$ & 4.304 & 0.00 & 3.720 & $0.0001 * *$ \\
\hline \hline P-value & $0.0001 * *$ & $0.167 \mathrm{NS}$ & $0.0001 * *$ & --- \\
\hline \hline \multicolumn{4}{r|}{$* *(\mathrm{P}<0.01), \mathrm{NS}$ : Non-significant. } \\
\hline
\end{tabular}


Table.2 Melting point, Yield and color of the prepared components

\begin{tabular}{|l|l|l|l|}
\hline Compound & M.P & Yield & Colour \\
\hline $\mathbf{A}$ & $(259-260) \mathrm{C}^{\circ}$ & $76-80 \%$ & cream-colored \\
\hline $\mathbf{B}$ & $(208-210) \mathrm{C}^{\circ}$ & $7-12 \%$ & pale yellow \\
\hline $\mathbf{C}$ & (above 300$) \mathrm{C}^{\circ}$ & $35 \%$ & Orange \\
\hline
\end{tabular}

Scheme.1 Synthesis of 2-mercapto-4-amino-5-carbethoxy- pyrimidine(5-pyrimidinecarboxylic acid, 4-amino-2-mercapto, ethyl ester) AND 2-mercapto-4-hydroxy-5-cyanopyrimidine(5pyremidinecarbonitrile, 4-hydroxy-2-mercapto)<smiles>CCO/C=C(/C#N)C(=O)OCC</smiles>

ethoxy methelene cyano acetate

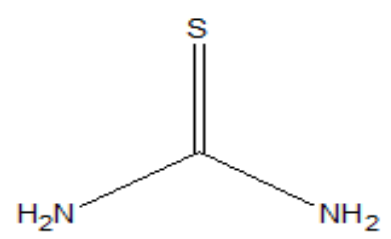

thiourea $\mathrm{C}_{2} \mathrm{H}_{5} \mathrm{ONa}$<smiles>COCc1cnc(S)nc1N</smiles>

2-Mercapto-4-Amino-5-Cabethoxy pyrimidine<smiles>N#Cc1cnc(S)nc1O</smiles>

2-Mercapto-4-Hydroxy-5-cyano pyrimidine 
Scheme.2 Synthesis of 6-amino-2mercapto-5 nitrosopyrimidin-4ol

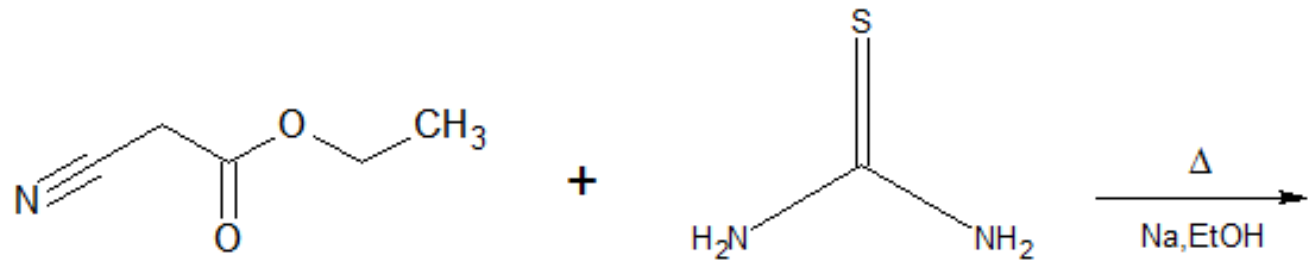

ethyl 2-cyanoacetate

thiourea<smiles>Nc1cc(O)nc(S)n1</smiles>

6-amino-2-mercaptopyrimidin-4-ol<smiles>Nc1nc(S)nc(O)c1[N+](=O)[O-]</smiles>

6-amino-2-mercapto-5-nitroso pyrimidin-4-ol

From above results and aforementioned discussion it can be concluded that synthesized some pyrimidine derivatives $(\mathrm{A}, \mathrm{B}, \mathrm{C})$ can be act as chelating agents for lead masking at lower concentration.

Compound in IR (KBr) $(\mathrm{Vmax} / \mathrm{Cm}-1)$ shows the following characteristic bands: the tow bands in $3325.28 \mathrm{~cm}^{-} 1$ and 3116.97 $\mathrm{cm}^{-1} 1$ were due to asymmetric and symmetric stretching vibration of ( $\mathrm{NH} 2)$ and the band in $3429.43 \mathrm{~cm}^{-} 1$ due to $(\mathrm{O}-\mathrm{H})$ group, band in $2569.18 \mathrm{~cm}^{-} 1$ due to (S-H) group. While the spectrum show the band in $1249.87 \mathrm{~cm}^{-} 1$ due to the $(\mathrm{N}=\mathrm{O})$ group. The band in 1631.78 due to $(\mathrm{C}=\mathrm{N})$ while the band in $1597.06 \mathrm{~cm}^{-} 1$ due to the $(\mathrm{C}=\mathrm{C})$ group.

\section{Study the effect components on the lead masking}

Chelating agents used to remove the lead by formation strong binds. Also it used as antidotes against lead toxicity (Sisombath,
2014). In table (1) showed that binding lead with three compound's which prepared.

We note from table (1) The concentration of lead in the table (10 and 5)Is a Standers lead, It has been prepared in vitro.

The C1 Back to the 2-mercapto-4-hydroxy5 -cyanopyrimidine. From the table we note that the ratio of lead is decrease after the Reactant between the solutions of standard lead and the compound No.1 and the decrease was high significant $(\mathrm{p}<0.01)$. And that the change between two values (from 7.41 to 4.304 ) is high significant.

C2 return to the 2-mercapto-4-amino-5carbethoxypyrimidine. Notes that the ratio of lead in the table is high declined when it 
Compared with other compounds. It high significant decrease $(\mathrm{p}<0.01)$. And that the change between two values ( from 0.2166 to 0.00 ) is non- significant.

In the final $\mathrm{C} 3$ back to the 6-amino2mercapto-5-nitrosopyrimidin-4-ol.

It show from the table this component was decrease the concentration of lead and the decrease was high-significant $(\mathrm{p}<0.01)$. And that the change between two values (from 6.832 to 3.720 ) is high significant. So it mean lead may be bind with $\mathrm{S}-\mathrm{H}$ group because it having high affinity with sulfhydryl group this compounds act as chelating agents (EDTA)for lead masking (Vallee, 1972).

\section{References}

Book, G. 2014. Compendium of Chemical Terminology. Int. Union of Pure and Appl. Chem.

Blatt, A.H., Lednicer, D., Mitscher, L.A., Overman, L.E., Corey, E.J., Cheng, X.M., Bols, M. 1963. Organic Syntheses, Collective Volume 4.

Chisolm, Jr, J.J. 1971. Treatment of lead poisoning. Modern treatment, 8(3), 593.
Flora, S.J., \& Pachauri, V. 2010. Chelation in metal intoxication. Int. J. Environ. Res. Public Health, 7(7), 2745-2788.

Lowry, J.A. 2010. Oral chelation therapy for patients with lead poisoning. Am. Acad. Pediatr., 116, 1036-1046.

Naji. T.S. and Ahmed, S.A. 2013. Synthesis and cytotoxic activity of some pyrimidine derivatives.

Sisombath, N. S., Jalilehvand, F., Schell, A. C., \& Wu, Q. 2014. Lead (II) binding to the chelating agent D-penicillamine in aqueous solution. Inorganic chem.., 53(23), 12459-12468.

Srivastava, S., \& Goyal, P. 2010. Detoxification of MetalsBiochelation. In Novel Biomaterials (pp. 11-20). Springer Berlin Heidelberg.

Skoog, D.A., West, D.M., Holler, F.J., \& Crouch, S.R. 2013. Fundamentals of Analytical Chemistry, Nelson Education.

Statistical Analysis System, SAS. 2012. User's Guide. Statistical. Version 9.1 ${ }^{\text {th }}$ ed. SAS. Inst. Inc. Cary. N.C. USA.

Vallee, B.L., \& Ulmer, D.D. 1972. Biochemical effects of mercury, cadmium, and lead. Annual Rev. Biochem., 41(1), 91-128.

\section{How to cite this article:}

Salman A. Ahmed and Zainab N. Eyada. 2016. Synthesis Some Pyrimidine Derivatives Act as Chelating Agents for Lead Masking. Int.J.Curr.Microbiol.App.Sci. 5(12): 765-771. doi: http://dx.doi.org/10.20546/ijcmas.2016.512.087 